\title{
THE MAIN TRENDS OF DISTANCE EDUCATION IN UKRAINE
}

\section{Андрей ГАЙДУК}

Abstract: The main elements advantages and shortcomings of distance educations are examining in the article. The perspectives of its development in modern Ukraine is forecasting also here.

Key words: Internet, distance education, information technologies, kinds of education, on-line.

\section{ОСНОВНЫЕ ТЕНДЕНЦИИ РАЗВИТЯ ДИСТАНЦИОННОГО ОБУЧЕНИЯ В УКРАИНЕ}

Аннотация: В статье рассматриваются и анализируются основные элементы, преимущества и недостатки дистанционного образования, а также прогнозируются перспективы его развития в современной Украине.

Ключевые слова: Интернет, дистанционное обучение, информационные технологии, форма обучения, он-лайн.

На фоне общемировых тенденций перехода от индустриального к информационному обществу, развитие дистанционной формы обучения является одним из перспективных направлений совершенствования системы образования в Украине. Следует понимать, что это совершенно новый этап в развитии образовательной индустрии нашей страны. Разразившийся экономический кризис поставил перед высшей школой всех европейских стран новую глобальную задачу - необходимость обеспечения доступа к высшему образованию все более широких слоев общества в условиях, когда относительный уровень финансирования высшей школы со стороны государства значительно снижен. И западная система высшего образования адекватно ответила на этот вызов созданием системы дистанционного обучения.

Дистанционное обучение предполагает такую организацию учебного процесса, когда студент учится самостоятельно с разработанной преподавателем программе и удален от него в пространстве или во времени, однако может вести диалог с ним с помощью средств телекоммуникации. Такое обучение в полной мере может служить реализации главных принципов образовательной политики современных европейских государств - направленности обучения и воспитания на индивидуальное развитие личности, удовлетворение и формирование ее нужд и интересов в соответствии с интересами общества. В свою очередь, применение методов дистанционного обучения предопределяет не только комфортное усвоение реципиентами материала с помощью новейших электронных учебников, видеолекций, мультимедийных презентаций, но и, что очень важно, - даёт возможность самим обучаемым непосредственно участвовать в онлайн семинарах и конференциях. Кроме того, такие возможности дистанционного обучения, как экстерриториальность, свободное структурирование времени делают такое обучение принципиально отличным от традиционных дидактических схем. Без преувеличения можно сказать, что с появлением дистанционного обучения изменилась вся философия образования в целом.

Цель данной статьи - вкратце обозначить основные тенденции развития дистанционного образования в Украине, сквозь призму использования его в современных практических целях, чтобы понять сущность, закономерности и перспективы развития этого явления, определить роль, которую оно должно сыграть в развитии нашего общества.

Исследованием проблем становления дистанционного образования в Украине занимались Н. Казаринова, С. Степаненко, В. Стрельников, Б. Шуневич, Г. Яценко, и другие. 
В развитии дистанционного обучения в Украине принято выделять два основных этапа: первоначальный и современный. Считается, что первоначальный этап - это период с начала 90-х годов прошлого столетия и по 1998 год включительно. Нормативно-правовой основой этого этапа развития дистанционного обучения в Украине стали такие основополагающие акты государственного управления, как Указ Президента Украины № 186/93 «О государственной политике информатизации Украины» от 31.05 .93 г., Постановление Кабинета Министров Украины № 605 «Вопросы информатизации» от 31.08 .94 г. и многие другие. Этот этап развития был ознаменован первоначальной разработкой и внедрением концепции гибкого дистанционного обучения на основе глобальных компьютерных коммуникаций. Тот, первоначальный этап развития дистанционного образования в Украине характеризовался началом использования информационных и коммуникативных технологий в обучении; созданием компьютерных телекоммуникационных лабораторий; разработкой дистанционных учебных программ и курсов, технологическим и методологическим обеспечением дистанционного обучения.

Начало современного периода развития дистанционного обучения в Украине принято относить к 1998 - 1999 г. Исследователи обосновано связывают это со вступлением в законную силу положений Закона Украины «O национальной программе информатизации» от 04.02.1998 г. В развитие этого закона в нашей стране в дальнейшем были приняты такие нормативные акты, как: Постановление Верховной Рады Украины № 1851-III «Об утверждении Национальной программы информатизации на 2000-2002 годы», Указ Президента Украины № 928/2000 «О мерах по развитию национальной составляющей глобальной сети Интернет и обеспечение широкого доступа к сети в Украине», Приказ № 293/2000 министра образования и науки «О создании Украинского центра дистанционного образования» (УЦДО), как структурного подразделения Национального технического университета Украины, а также была утверждена в декабре 2000 года «Концепция дистанционного образования в Украине». С этого момента интеллектуальные информационные технологии начали активно использоваться для поддержки непрерывного обучения. Собственно с началом нынешнего, современного этапа развития дистанционного образования в Украине и начали внедряться информационно-обучающие среды, виртуальные лаборатории, сверхсовременные мультимедийные технологии, виртуальные сообщества.

В настоящий момент дистанционное образование в Украине реализуется через систему дистанционного обучения, которая, в свою очередь, является составной частью системы образования Украины, со своей нормативно-правовой базой, организационно оформленной структурой, кадровым, системотехническим, материальнотехническим и финансовым обеспечением. Совершенно очевидно, что на данный момент, дистанционное обучение в Украине может полноценно развиваться только при наличии следующих компонентов:

- _ развитой нормативно-правовой базы;

- необходимого количества учебных заведений (центров, кафедр, факультетов, институтов или университетов дистанционного обучения);

студентов;

преподавателей; квалифицированных
$-$
учебных программ и курсов;
$-$ соответствующей

материально-технической базы (аппаратного и программного обеспечения, высокоскоростных линий связи) и стабильной финансовой поддержки.

Пожалуй, одной из острых проблем дистанционного образования в Украине сегодня является ее недостаточное финансирование. По этой же причине не отвечает современным условиям развития высшего образования система повышения квалификации педагогических и научнопедагогических работников высшей школы. При существующем остром дефиците кадров в государственном бюджете почти не предусматриваются средства на повышение квалификации или получения новой 
специальности работниками образовательной отрасли за государственные средства. В условиях экономического кризиса учебные заведения дистанционного образования сейчас в основном находятся на самофинансировании, самостоятельно решают вопросы учебно-методического обеспечения. Значительной помощью во внедрении новой технологии обучения для высших учебных заведений нашей страны является то, что они участвуют в различных международных проектах, сотрудничают с родственными отечественными и зарубежными учебными заведениями, которые также заняты проблемой внедрения новых методов и технологий в своих учебных заведениях. Еще одним способом улучшения материально-технической базы высших учебных заведений является их кооперация с другими учебными заведениями. Значительную пользу дало бы также стимулирование украинским государством спонсорской деятельности отечественных и зарубежных организаций, предприятий, фондов для оснащения учебных заведений необходимой компьютерной техникой современным оборудованием, линиями связи. К великому сожалению - наше государство устранилось от решения данной проблемы. Развитие такой важной составляющей отечественного образования как дистанционное обучение на сегодняшний момент практически полностью держится на энтузиазме отдельных личностей.

На наш взгляд, следует обратить внимание ещё на одну проблему: понятно всем, что качество курсов дистанционного образования, которые предоставляются в электронном виде, должна быть не ниже качество традиционного обучения. Следовательно, напрашивается вывлд: в первую очередь, необходимо тщательно подобрать преподавательский состав для работы на онлайновых курсах и обеспечить им необходимую подготовку и техническую поддержку.

Необходимо также учесть, что дистанционное обучение, по своей сути и отдельным характеристикам, существенно отличается от традиционного обучения в Украине. Подготовка к использованию дистанционных учебных курсов должна начинаться c глубокого анализа: целей обучения, дидактических возможностей новых технологий передачи учебной информации, требований к технологиям дистанционного обучения с точки зрения обучения конкретным дисциплинам. Соответственно студенты, обучающиеся дистанционно, также нуждаются в системе академической и технической поддержки. Значительные усилия в обозримом будущем необходимо будет приложить к разработке среды обучения, также необходимо постоянно контролировать состояние технологической базы своевременно используя возможность ее совершенствования.

Подводя некоторые итоги, считаем возможным утверждать следующее:

1. На сегодняшний день в Украине сформировался довольно большой контингент будущих студентов, который серьезно заинтересован в организации и надёжном функционировании системы дистанционного образования в высших учебных заведениях страны.

2. В последнее время в нашей стране существенно возросло количество пользователей компьютеров, каналов связи и расширился доступ в Интернет, что способствует дальнейшему, более широкому внедрению технологии дистанционного обучения.

3. Государству очень важно стимулировать работу ученых и практиков, направленную на разработку соответствующих нормативноправовых документов, создание гибкой и адекватной системы администрирования и контроля знаний, разработку теории дистанционного обучения. Перспективы дальнейших исследований по данной проблеме должны идти в направлении поиска наиболее продуктивного информационного обслуживания потребностей человека именно в учебно-педагогическом процессе.

Успешное решение существующих проблем развития дистанционного образования в Украине, безусловно, будет способствовать повышению качества и уровня доступности высшего образования, интеграции национальной системы образования в научную, производственную, социально-общественную и культурную информационную европейского сообщества. 


\section{Литература}

[1] ПОЛАТ Е. Новые педагогические $u$ информационные технологии в системе образования. М.: Академия, 2005. - 272 с.

[2] ПОЦУЛКО О. Дистаниійна освіта в Украӥні. [Електронний ресурс]. Режим доступу: http://www.nbuv.gov.ua/

[3] СТЕПАНЕНКО С. Про трансформацію системи заочної освіти в умовах інтеграції в Європейський освітній простір. Вищза школа. № 2. 2007. С. 31-37.

[4] ХУТОРСКОЙ А. Научно-практические предпосылки дистанционной педагогики. Открытое образование. 2001. № 2. С. 30-35.
[5] ШУНЕВИЧ Б. Дистанційна освіта: Теорії індустріалізації викладання. Педагогіка і психологія професійної освіти. № 5. 2002. С. 45-50.

[6] ЯЦЕНКО Г. Комунікативна сутність дистанційного навчання: постановка проблеми. Вища освіта Украӥни. № 3. 2007. С. 70-74.

Assessed by: Prof. Dr. A. A. Ligockij

GAIDUK Andrey, UA, Ph.D., associate professor, Department of criminal and administrative law, Academy of Advocacy of Ukraine, Kiyv 